\title{
Possible contribution of aminopeptidase N (APN/CD13) to migration and invasion of human osteosarcoma cell lines
}

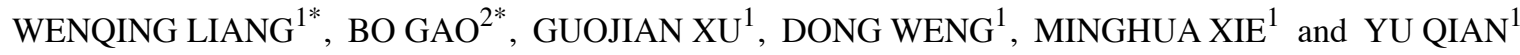 \\ ${ }^{1}$ Department of Orthopedics, Shaoxing People's Hospital, Shaoxing, Zhejiang 312000; \\ ${ }^{2}$ Department of Orthopedics, The 306th Hospital of PLA, Beijing 100101, P.R. China
}

Received July 25, 2014; Accepted September 2, 2014

DOI: $10.3892 /$ ijo.2014.2664

\begin{abstract}
Osteosarcoma is the most common primary malignancy of the bone. Aminopeptidase N (APN/CD13), a $\mathrm{Zn}^{+2}$-dependent ectopeptidase localized on the cell surface, is widely considered to influence the invasion mechanism. This study explores the potential involvement of APN in migration and invasion of human osteosarcoma cells in vitro using inhibitors and activators of APN. Cells treated with APN inhibitor bestatin displayed decreased migration and invasion in a Boyden chamber Transwell assay. Western blotting revealed reduced levels of mitogen-activated protein kinase (MAPK) and phosphatidylinositol 3-kinase (PI3K) pathway proteins, reduced phosphorylation of p38, ERK1/2 and JNK and decreased levels of NF- $\kappa$ B. Bestatin treatment also lowered APN, matrix metalloproteinase (MMP)-2 and -9 enzymatic activity and their mRNA expression. Reduced MMP-2 and -9 protein levels were also observed. By comparison, cells treated with cytokine interleukin-6 (IL-6), a stimulator of APN, displayed increased migration and invasion. Western blotting revealed increased levels of MAPK and PI3K pathway proteins, phosphorylated p38, ERK1/2 and JNK, and NF- $\mathrm{NB}$. IL-6 treatment also increased APN and MMP-2 and -9 enzymatic activity. An increase of APN, MMP-2 and -9 mRNA levels, and MMP-2 and -9 protein levels was also observed. Together these experiments reveal potential enzymatic and signalling roles for APN in osteosarcoma and establish a starting point for an in-depth analysis of the role of APN in regulating invasiveness. A deeper knowledge about the regulatory mechanisms of APN may contribute to the development of anti-metastatic therapies.
\end{abstract}

Correspondence to: Dr Yu Qian, Department of Orthopedics, Shaoxing People's Hospital, 568 Zhongxing North Road, Shaoxing, Zhejiang 312000, P.R. China

E-mail: doctorqy@126.com

*Contributed equally

Key words: osteosarcoma, metastasis, aminopeptidase N, matrix metalloproteinase

\section{Introduction}

Osteosarcoma, the most common primary bone cancer, occurs predominantly in growing adolescents and young adults and is characterized by frequent distant metastasis, particularly to the lung (1). Although the overall survival rate for osteosarcoma has increased to $\sim 70 \%,<30 \%$ of patients presenting with metastases survive 5 years after the initial diagnosis (2). Since pulmonary metastasis is the major cause of death in osteosarcoma, identifying molecular alterations that lead to metastasis is essential for developing novel therapies.

The first step in metastasis is the migration from the primary tumour site and invasion through the basement membrane. The degradation of the extracellular matrix contributes to the ability of osteosarcoma cells to metastasize. In osteosarcoma the gelatinases matrix metalloproteinase (MMP)-2 and -9 promote invasion and metastasis (3-5), intracellular protease m-calpain modulates cell adhesion and motility (6), and urokinase plasminogen activator (uPA) and its receptor uPAR promote cell adhesion, migration and invasion through the activation of plasminogen and pro-MMPs (7). Integrin- $\beta 4(8)$ and the Wnt/ $\beta$-catenin $(9,10)$ and Notch $(11,12)$ signalling pathways, both of which activate metalloproteinases $(13,14)$, have also been shown to promote osteosarcoma metastasis. Finally, secreted factors, including the cytokine interleukin-6 (IL-6) (15), parathyroid hormone (PTH), PTH peptides and the PTH receptor (PTHR) $(16,17)$, autocrine motility factor (AMF) $(18,19)$ and matricellular protein Cyr61 (20) are known to promote metastasis.

The expression of both soluble and membrane bound APN is strongly correlated with the invasive capacity of numerous tumour cell types (21-23) and APN is widely believed to influence the invasion mechanism. A previous study showed that APN activity is correlated with IL-6-mediated osteosarcoma invasiveness (24). APN is a zinc-dependent membrane-bound aminopeptidase with a short N-terminal cytoplasmic domain, a single transmembrane part and a large extracellular domain containing the active site. APN is a multifunctional enzyme, which can operate as an enzyme for peptide cleavage, a receptor in endocytosis and/or a signalling molecule in signal transduction. Each of these three mechanisms elicits a different biological effect (23). APN overexpression or altered enzymatic activity has been reported in skin, ovary, thyroid, lung, stomach, colon, kidney, 
bone and prostate neoplasias $(25,26)$. The mechanism by which APN participates in cell invasion is linked to its enzymatic activity, but APN has also been shown to facilitate signal transduction in endothelial invasion (27).

It has been demonstrated that IL-6 plays an important role in the progression and invasion of tumours by stimulating MMP production $(28,29)$. MMPs have pivotal roles in the degradation of extracellular matrix, and thereby enhance the invasive and metastatic potential in cancer $(30,31)$. In human osteosarcoma, MMP-2 has been implicated in the metastatic process (32) and MMP-9 has been shown to be associated with poor prognosis (33-35).

In this study we investigate the effect of APN inhibition and activation on osteosarcoma cell lines using APN inhibitor bestatin and APN activator IL-6. This study creates a platform to further explore APN involvement in osteosarcoma metastasis and identify target signalling networks for novel therapeutic strategies.

\section{Materials and methods}

Cell culture. The human osteosarcoma cell lines MG63 and U-2 OS were obtained from the Shanghai Institute of Cell Biology (Shanghai, China). The cells were grown under standard conditions in RPMI-1640 and supplemented with 10\% heat-inactivated FBS and antibiotics/antimycotics (all from Gibco-BRL, Eggenstein, Germany). They were incubated at $37^{\circ} \mathrm{C}$ in a $\mathrm{CO}_{2}$ incubator, released from the culture surface using trypsin/EDTA (Gibco-BRL) and counted in a haemocytometer.

Cytokines and APN inhibitors. IL-6 and sIL-6R were purchased from R\&D Systems (Minneapolis, MN, USA). Bestatin was purchased from Sigma (St. Louis, MO, USA). All treatments with IL- 6 were at $1 \mathrm{nM}$ and included $15 \mathrm{nM}$ sIL-6R, which was added to achieve a stable effect in osteoblastic cells (36-39).

RNA isolation and cDNA synthesis. MG63 or U-2 OS cells $\left(1 \times 10^{6}\right.$ cells/well) were placed in 6-well plates and incubated with factors (IL-6, sIL-6R or bestatin) for the times indicated. Cells were collected and total RNA was extracted from each treatment using the Qiagen RNeasy Mini kit (Qiagen Inc., Valencia, CA, USA). RNA samples were reverse-transcribed at $42^{\circ} \mathrm{C}$ using the High Capacity cDNA Reverse Transcription kit for $30 \mathrm{~min}$ according to the protocol of the supplier (Applied Biosystems, Foster City, CA, USA).

Absolute quantitation of APN expression by competitive $R T$-PCR. The internal competitive standard RNA was obtained using the method designed by Kehlen et al and composite primers were synthesized as shown in Table I (40). For cDNA synthesis, 1,000, 500, 50, 10 or 1 pg APN competitor RNA were added to $5 \mu \mathrm{g}$ total RNA and reverse-transcribed at $42^{\circ} \mathrm{C}$ using the High Capacity cDNA Reverse Transcription kit for 30 min according to the protocol of the supplier (Applied Biosystems). Two microliters of cDNA was diluted in $50 \mu \mathrm{l}$ of PCR reaction solution containing primers 3 and 4 . The PCR reaction was performed according to the manufacturer's standard protocol (Qiagen Inc., Hilden, Germany) in a thermal
Table I. Primers used in competitive PCR.

\begin{tabular}{ll}
\hline Primers & \multicolumn{1}{c}{ Sequences } \\
\hline 1 & GTG ATG GCA GTG GAT GCA CAG CTT CCT \\
& GTC CGA GGA CTG TA \\
2 & GAT TTA GGT GAC ACT ATA GAA TAC GTG \\
3 & ATG GCA GTG GAT GCA C \\
4 & GTG ATG GCA GTG GAT GCA C \\
\hline
\end{tabular}

cycler (MaxiCycler PTC-100; MJ Research, Inc., Watertown, MA, USA) for 35 cycles of $60 \mathrm{sec}$ at $94^{\circ} \mathrm{C}, 60 \mathrm{sec}$ at $60^{\circ} \mathrm{C}$, and $60 \mathrm{sec}$ at $72^{\circ} \mathrm{C}$. Each reaction product $(10 \mu \mathrm{l})$ was run on a $1.5 \%$ agarose gel containing $0.1 \% \mu \mathrm{g} / \mathrm{ml}$ ethidium bromide in TAE buffer. The relative intensities of the bands corresponding to the target (573 bp) and internal standard (434 bp) PCR products were visualized with UV light. The relative amounts of target and internal standard products were calculated by densitometric analysis using ImageMaster 1D Prime software (Amersham Pharmacia Biotech, Freiburg, Germany). The ratio of standard to target amplification products was graphed as a function of the initial amount of internal standard, and lines were drawn from a linear regression analysis using InStat (GraphPad Software, Inc., San Diego, CA, USA). The initial amount of target was calculated from the point where the amount of amplified target equals the amount of amplified standard (ratio D 1). The analysis was performed in triplicate.

Quantitative PCR. The following quantitative PCR conditions were used: $2 \mathrm{~min}$ at $50^{\circ} \mathrm{C}, 10 \mathrm{~min}$ at $95^{\circ} \mathrm{C}$, and 40 cycles of $15 \mathrm{sec}$ at $95^{\circ} \mathrm{C}, 1 \mathrm{~min}$ at $60^{\circ} \mathrm{C}$ using $1 \mu \mathrm{l}$ of the cDNA reverse-transcribed as described above, 2X SYBR-Green PCR Master Mix (Applied Biosystems), and $200 \mathrm{nM}$ forward and reverse primers. The primer sequences were APN forward, GTTCTCCTTCTCCAACCTCATC and reverse, CTGTTTC CTCGTTGTCCTTCT; MMP-2 forward, CCCCAGACAGGT GATCTTGAC and reverse, GCTTGCGAGGGAAGAAG TTG; MMP-9 forward, CGCTGGGCTTAGATCATTCC and reverse, AGGTTGGATACATCACTGCATTAGG; GAPDH forward, ACACCCACTCCTCCACCTTT and reverse, TAG CCAAATTCGTTGTCATACC. Each assay was run on an Applied Biosystems 7300 Real-Time PCR System in triplicate, and expression fold changes were derived using the comparative threshold cycle (CT) method $(41,42)$.

Enzyme activity. APN activity was assayed using the substrate alanine p-nitroanilide (Ala-pNA) at a final concentration of $1.5 \mathrm{mM}$. Confluent cell monolayers in 48 -well plates were rinsed three times and incubated at $37^{\circ} \mathrm{C}$ for $20-40 \mathrm{~min}$ with pre-warmed substrate. Supernatant p-nitroanilide was measured at an OD of $405 \mathrm{~nm}$ by a microplate reader (Anthos Labtec Instruments GmbH, Salzburg, Austria). Assays were run in triplicate, in parallel with cell- and substrate-free blanks. The cells were detached from the plates and counted. Catalytic activity was expressed as pkat $/ 10^{6}$ cells. 
A

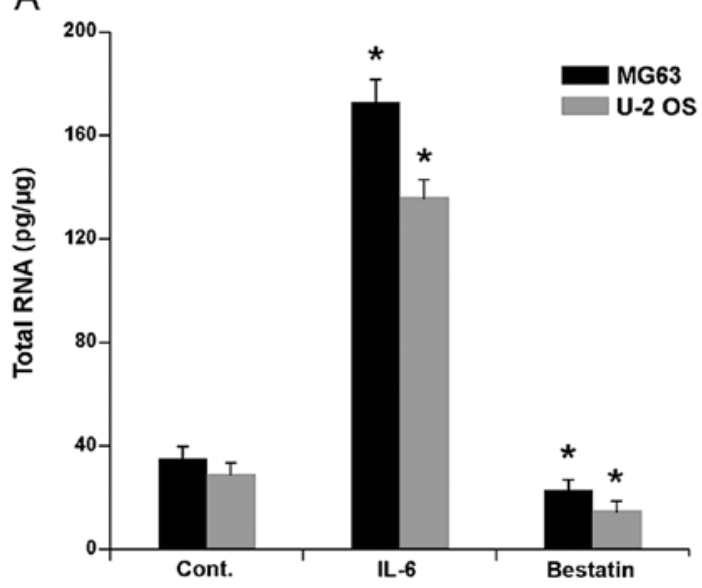

B

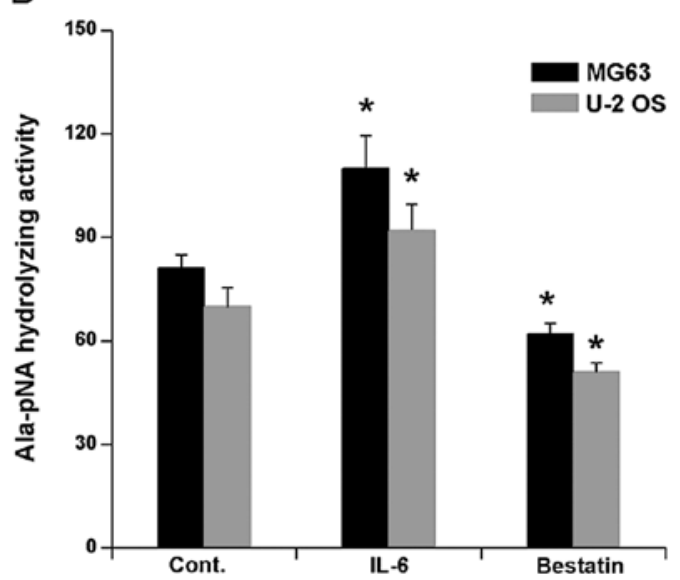

Figure 1. Effect of interleukin-6 (IL-6) and bestatin on APN expression and hydrolysing activity in human osteosarcoma cell lines MG63 and U-2 OS. Cells were treated for $24 \mathrm{~h}$ with IL-6 $(1 \mathrm{nM})$ or bestatin $(100 \mu \mathrm{M})$. (A) Absolute mRNA expression of APN in osteosarcoma cell lines. (B) Alanine p-nitroanilide (Ala-pNA) hydrolysing activity expressed as pkat $/ 10^{6}$ cells. ${ }^{*}$ Statistically significant $(\mathrm{P}<0.05)$.

A

Cont.

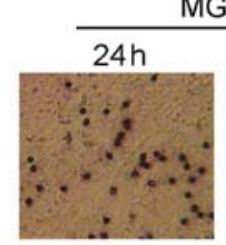

IL-6
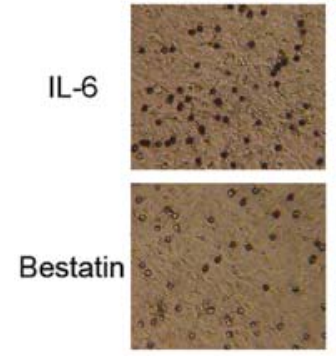

MG63

$48 \mathrm{~h}$
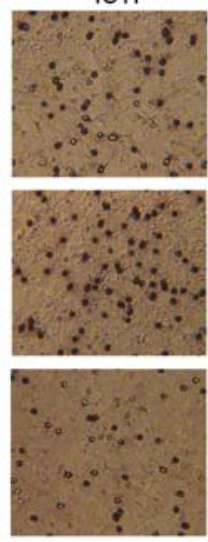

B

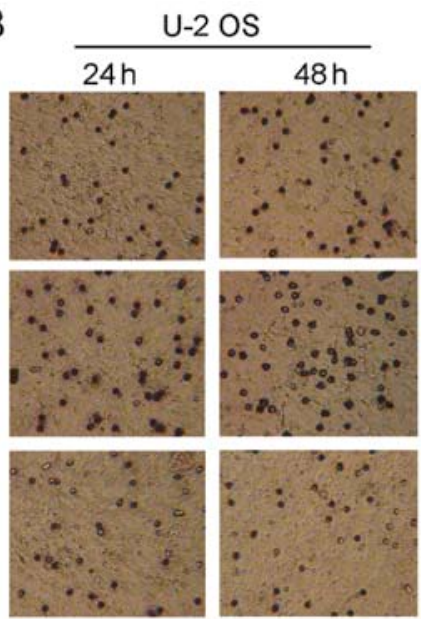

C

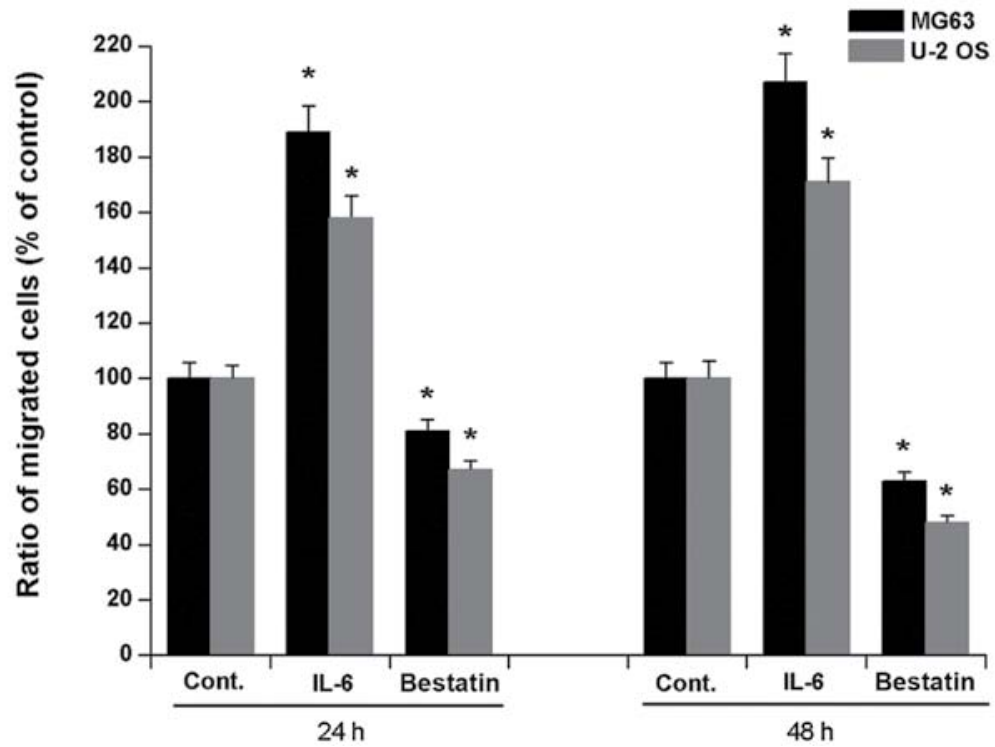

Figure 2. Effect of interleukin-6 (IL-6) and bestatin on invasive potential of MG63 and U-2 OS cells in a Boyden chamber (Matrigel-coated polycarbonate filters; pore size, $8 \mu \mathrm{m})$ treated with IL-6 $(1 \mathrm{nM})$ or bestatin $(100 \mu \mathrm{M})$ for 24 and $48 \mathrm{~h}$. Photomicrographs of crystal violet stained (A) MG63 and (B) U-2 OS cells located on the underside of the porous polycarbonate membrane. (C) Quantification by microscopy of MG63 and U-2 OS cells located on the underside of the porous polycarbonate membrane. The average of three independent experiments with duplicate biological samples is given. ${ }^{*} \mathrm{P}<0.05$ compared with the untreated control. 
Gelatin zymography. MMP-2 and -9 activity was determined by gelatin zymography after exposure to IL-6 or bestatin. Cells ( $1 \times 10^{6}$ cells/well) were plated in 12-well tissue culture plates and incubated in serum-free McCoy's 5A medium in the presence of $1 \mathrm{nM}$ IL- 6 or $100 \mu \mathrm{M}$ bestatin for 24 and $48 \mathrm{~h}$. The conditioned medium was then collected and separated by electrophoresis on $10 \%$ SDS-PAGE containing $0.2 \%$ gelatin (Sigma). At the end of electrophoresis, the gels were soaked twice in $2.5 \%$ Triton $\mathrm{X}-100$ in $\mathrm{dH}_{2} \mathrm{O}$ at $25^{\circ} \mathrm{C}$ for a total of $60 \mathrm{~min}$, then incubated in substrate buffer $(50 \mathrm{mM}$ Tris $\mathrm{HCl}, 5 \mathrm{mM} \mathrm{CaCl}, 0.02 \% \mathrm{NaN}_{3}$ and $1 \%$ Triton $\mathrm{X}-100$, $\mathrm{pH} 8.0$ ) at $37^{\circ} \mathrm{C}$ for $18 \mathrm{~h}$. Bands corresponding to MMP-2 and -9 activity were visualized by negative staining using $0.2 \%$ Coomassie Blue in $50 \%$ methanol and $10 \%$ acetic acid as described elsewhere $(43,44)$. Bands were quantified using NIH ImageJ software (NIH, Bethesda, MD, USA) as previously described $(45,46)$.

In vitro migration and invasion assays. Cell mobility was determined in migration and invasion assays through 24-well Transwell inserts ( $8 \mathrm{~mm}$ pore size) coated with $30 \mu \mathrm{g}$ type 1 collagen (both from Millipore, Billerica, MA, USA) (migration assay) or Matrigel (BD Biosciences, Bedford, MA, USA) (invasion assay) $(41,44)$. U-2 OS and MG63 cells were maintained in serum-free medium for $24 \mathrm{~h}$, after which they were trypsinized, resuspended in serum-free McCoy's 5A medium and placed in the upper chamber of the Transwell insert $\left(5 \times 10^{4}\right.$ cells/well). Cells were then treated for 24 or $48 \mathrm{~h}$ with $1 \mathrm{nM}$ IL-6 or $100 \mu \mathrm{M}$ bestatin. McCoy's 5A medium containing $10 \%$ FBS was then placed in the lower chamber. Non-migrating cells in the upper chamber were removed by wiping with a cotton swab. Cells that had penetrated the filter and were located on the lower chamber side of the filter were fixed with $4 \%$ formaldehyde in PBS, stained with $2 \%$ crystal violet in $2 \%$ ethanol and counted under a light microscope at x200 magnification.

$N F-\kappa B$ immunofluorescence. Cells placed on 6-well chamber slides were treated with $1 \mathrm{nM}$ IL- 6 or $100 \mu \mathrm{M}$ bestatin for $24 \mathrm{~h}$, immunofluorescence-labeled using a Cellular NF- $\mathrm{B}$ Translocation kit (Beyotime Institute of Biotechnology, Jiangsu, China) according to the manufacturer's protocol. Briefly, after fixing, the cells were stained using anti-NF- $\mathrm{B}$ p65 (1:100) overnight and then stained with $\mathrm{Cy} 3$ fluorescein-conjugated secondary antibody followed by nuclear counterstain propidium iodide. Photomicrographs were obtained using a Leica TCS SP2 confocal spectral microscope.

Western blotting. U-2 OS cells $\left(1 \times 10^{6}\right.$ cells/well) were placed in 6-well plates and each well was incubated for 24 or $48 \mathrm{~h}$ in $1 \mathrm{nM}$ IL-6 or $100 \mu \mathrm{M}$ bestatin. Cells were harvested and lysed with ice-cold $50 \mathrm{mM}$ potassium phosphate buffer $(\mathrm{pH} 7.4)$ containing $2 \mathrm{mM}$ EDTA and $0.1 \%$ Triton X-100, sonicated and then centrifuged at $13,000 \mathrm{~g}$ for $10 \mathrm{~min}$ at $4^{\circ} \mathrm{C}$. The supernatant was collected and total protein was determined using a Bio-Rad Protein Assay kit (Bio-Rad, Hercules, CA, USA) with bovine serum albumin (BSA) as the standard. At the end of electrophoresis, proteins were electrotransferred to nitrocellulose membranes, blotted with primary antibody against GRB2, PI3K, AKT, PKC, p38, NF-кB p65, p38, ERK1/2, JNK,
MMP-2, MMP-9, p-p38, p-ERK1/2 or p-JNK (Cell Signaling Technology, Inc., Danvers, MA, USA) then washed and stained with secondary antibody. Bands were visualized with an enhanced chemiluminescence reagent (ECL ${ }^{\mathrm{TM}}$; Amersham Biosciences Corp., Piscataway, NJ, USA) and quantified using an NIH Image analyzer (NIH).

Statistical analysis. Data are presented as the means \pm standard deviation (SD) from at least three independent experiments. Differences between groups were determined using Student's t-test. $\mathrm{P}<0.05$ was considered to indicate a statistically significant result.

\section{Results}

APN mRNA expression and hydrolysing activity is affected by IL- 6 and bestatin. The treatment of human osteosarcoma cell lines HOS and MG63 with cytokine IL-6 has been shown to upregulate APN mRNA (24). To confirm and extend these observations we first determined APN mRNA expression in human osteosarcoma cells lines U-2 OS and MG63 after exposure to IL-6 (1 nM) for $24 \mathrm{~h}$. Competitive PCR showed that APN mRNA expression in both cell lines increased significantly (Fig. 1A). We next investigated whether bestatin, a widely used and potent inhibitor of APN, inhibited APN mRNA expression. A $24 \mathrm{~h}$ exposure of U-2 OS and MG63 to $100 \mu \mathrm{M}$ bestatin decreased the mRNA levels slightly, but nevertheless significantly (Fig. 1A).

It has previously been shown that IL- 6 treatment of human osteosarcoma cell lines MG63 and HOS significantly increased Ala-pNA hydrolysing activity (24). We confirmed and extended these observations by investigating APN Ala-pNA hydrolysing activity in the cells lines U-2 OS and MG63 after a $24 \mathrm{~h}$ treatment with IL-6 $(1 \mathrm{nM})$ or bestatin $(100 \mu \mathrm{M})$. As expected, IL-6 treatment significantly increased Ala-pNA hydrolysing activity in both cell lines (Fig. 1B). In contrast, the bestatin treatment significantly decreased Ala-pNA hydrolysing activity (Fig. 1B). Together these data confirm that IL-6 treatment activates, whereas bestatin treatment inhibits, APN hydrolysing activity and APN mRNA expression in human osteoblast cell lines.

Osteosarcoma cell migration and invasion after IL-6 and bestatin treatment. It has previously been demonstrated that a $24 \mathrm{~h}$ treatment of human osteosarcoma cell lines HOS and MG63 with IL-6 $(1 \mathrm{nM})$ or bestatin $(100 \mu \mathrm{M})$ enhances or represses their invasive potential, respectively (24). To confirm and extend these observations we assessed the invasive potential of cell lines U-2 OS and MG63 exposed to IL-6 (1 nM) or bestatin $(100 \mu \mathrm{M})$ for 24 or $48 \mathrm{~h}$. The invasiveness of both MG63 and U-2 OS cells significantly increased upon exposure to IL-6 and significantly decreased upon exposure to bestatin after both 24 and $48 \mathrm{~h}$ (Fig. 2). We also assessed the migration potential of MG63 and U-2 OS when exposed to IL-6 (1 nM) or bestatin $(100 \mu \mathrm{M})$ for 24 or $48 \mathrm{~h}$. The migration of both U-2 OS and MG63 cells significantly increased upon exposure to IL-6 and significantly decreased upon exposure to bestatin after both 24 and $48 \mathrm{~h}$ (Fig. 3). The data shown here confirm that APN stimulator IL-6 and APN inhibitor bestatin enhance and reduce cell invasiveness and migration, respectively. Since 
A
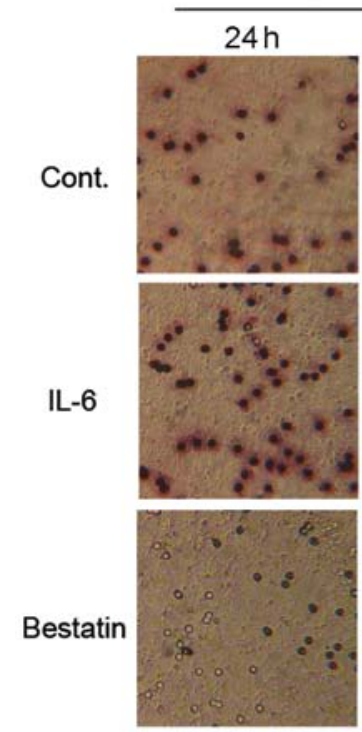

MG63
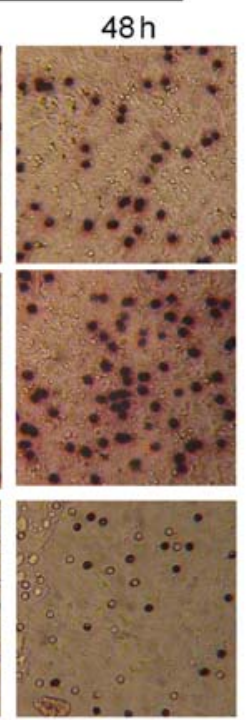

B
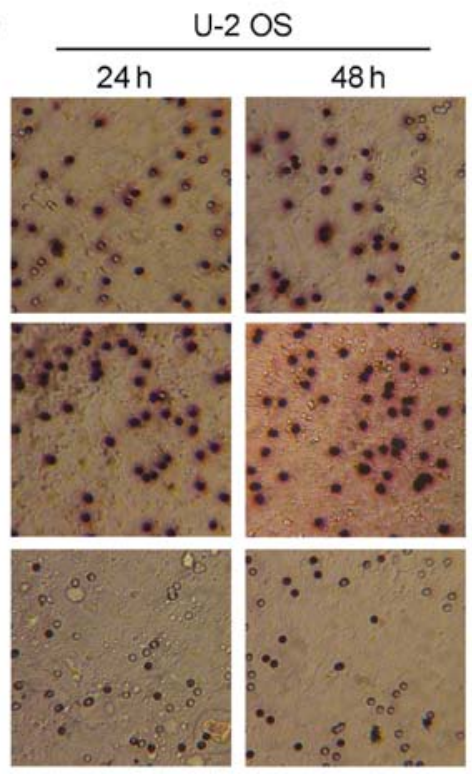

C

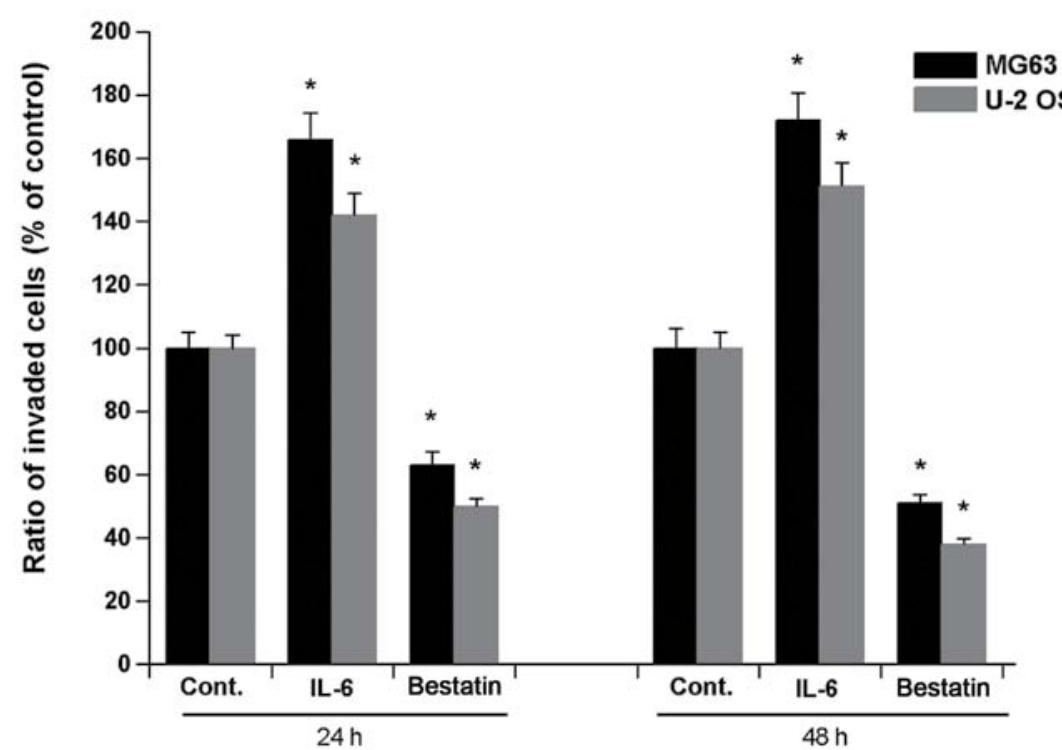

Figure 3. Effect of interleukin-6 (IL-6) and bestatin on cell migration of MG63 and U-2 OS cells in a Boyden chamber (collagen-coated polycarbonate filters; pore size, $8 \mu \mathrm{m})$ treated with IL-6 $(1 \mathrm{nM})$ or bestatin $(100 \mu \mathrm{M})$ for 24 and $48 \mathrm{~h}$. Photomicrographs of crystal violet stained (A) MG63 and (B) U-2 OS cells located on the underside of the porous polycarbonate membrane. (C) Quantification by microscopy of MG63 and U-2 OS cells located on underside of the porous polycarbonate membrane. The average of three independent experiments with duplicate biological samples is given. "P<0.05 compared with the untreated control.

the invasive potential of cell lines HOS and MG63 correlates with the relative enzymatic activity of APN (24), it is possible that the increased invasive potential and migration of U-2 OS and MG63 cells observed here is also due to increased APN activity.

Effect of IL-6 and bestatin on MMP-2 and -9 activity. To investigate whether APN regulates MMP-2 and -9 activity in osteosarcoma cell lines, we measured MMP-2 and -9 enzyme activity by gelatin zymography after inhibiting APN in MG63 and U-2 OS cells with bestatin (100 $\mu \mathrm{M})$ for 24 and $48 \mathrm{~h}$. We found that both 24- and 48-h bestatin treatments decreased MMP-2 and -9 activity (Fig. 4A and B). These results suggest that the decreased invasiveness of bestatin-treated cells could be due APN's reduced activation of MMP-2 and -9. By comparison, a 24 and $48 \mathrm{~h}$ incubation of MG63 and U-2 OS cells with IL-6 (1 nM) increases MMP-2 and -9 activity (Fig. 4A and B). Together these results raise the possibility that the increased invasiveness of MG63 and U-2 OS by IL-6 could be due to IL-6's activation of MMP-2 and -9 via APN activation.

IL-6 and bestatin alter levels and phosphorylation states of signalling proteins. Cell invasion and migration are orchestrated by multiple signalling cascades, including the mitogen-activated protein kinase (MAPK) and phosphatidylinositol 3-kinase (PI3K) pathways $(47,48)$. We determined the effect of APN inhibition on protein levels and phosphorylation states of MAPK and PI3K signalling pathway members by western blotting. The treatment of MG63 (Fig. 5) and 
A

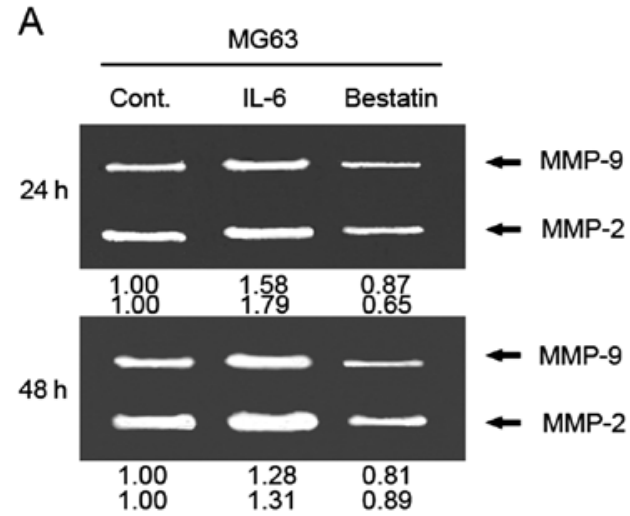

B

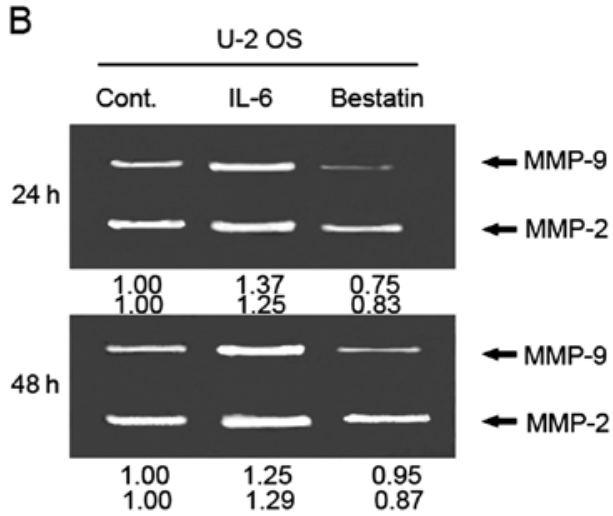

Figure 4. Effect of interleukin-6 (IL-6) and bestatin on matrix metalloproteinase (MMP)-2 and -9 enzyme activities in (A) MG63 and (B) U-2 OS cells treated with IL-6 $(1 \mathrm{nM})$ or bestatin $(100 \mu \mathrm{M})$ for 24 and $48 \mathrm{~h}$. Representative zymogram depicting the activity of secreted MMP-2 and -9 using conditioned medium. MMP-2 and -9 activities were determined by densitometric analysis and expressed as a percentage of the control (100\%).

A

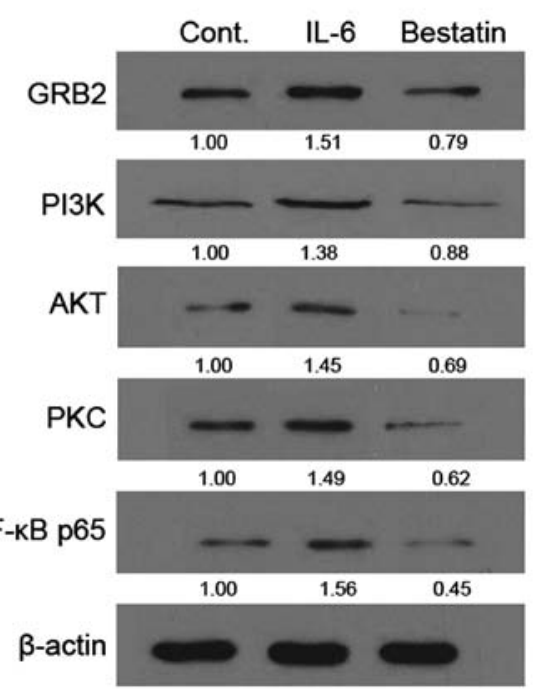

C

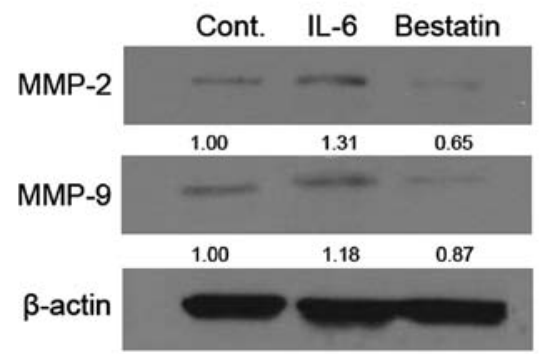

B
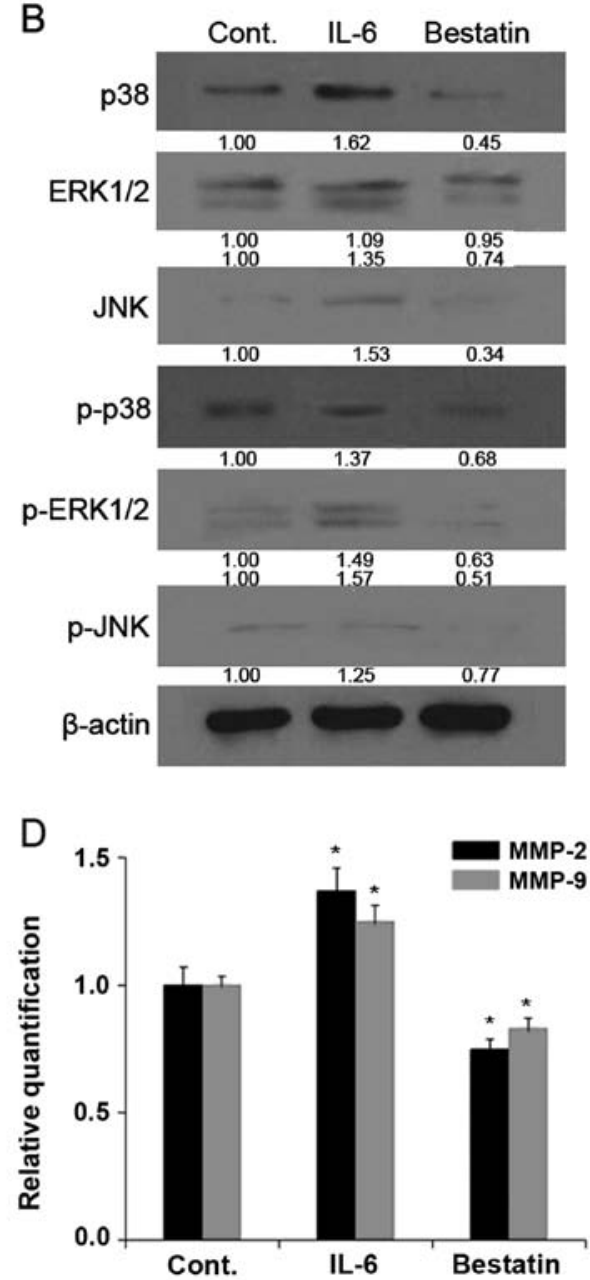

Figure 5. Mitogen-activated protein kinase (MAPK) and phosphatidylinositol 3-kinase (PI3K) pathway proteins in interleukin-6 (IL-6)- and bestatin-treated MG63 cells. Cells were treated with IL-6 $(1 \mathrm{nM})$ or bestatin $(100 \mu \mathrm{M})$ for $24 \mathrm{~h}$. The levels of (A) GRB2, PI3K, AKT, PKC, NF-kB p65; (B) p38, ERK1/2, JNK, p-p38, p-ERK1/2 and p-JNKp; (C) matrix metalloproteinase (MMP)-2 and -9 are depicted by SDS-PAGE and western blotting. Results shown here are representative of at least three independent experiments. (D) Relative quantification of MMP-2 and -9 by real-time PCR. The ratios between MMP-2, -9 and GAPDH mRNA are displayed and data represent the mean \pm standard deviation (SD) in duplicate of at least three independent experiments. ${ }^{*} \mathrm{P}<0.05$ was considered significant. $\beta$-actin, control.

U-2 OS (Fig. 6) cell lines with bestatin $(100 \mu \mathrm{M})$ for $24 \mathrm{~h}$ resulted in decreased levels of GRB2, PI3K, AKT, PKC, NF-kB p65 (Figs. 5A and 6A), p38, ERK1/2, JNK, p-p38,
p-ERK1/2 and p-JNK (Figs. 5B and 6B). By comparison, the treatment of MG63 and U-2 OS cell lines with APN stimulator IL-6 for $24 \mathrm{~h}$ resulted in increased levels of GRB2, PI3K, 
A

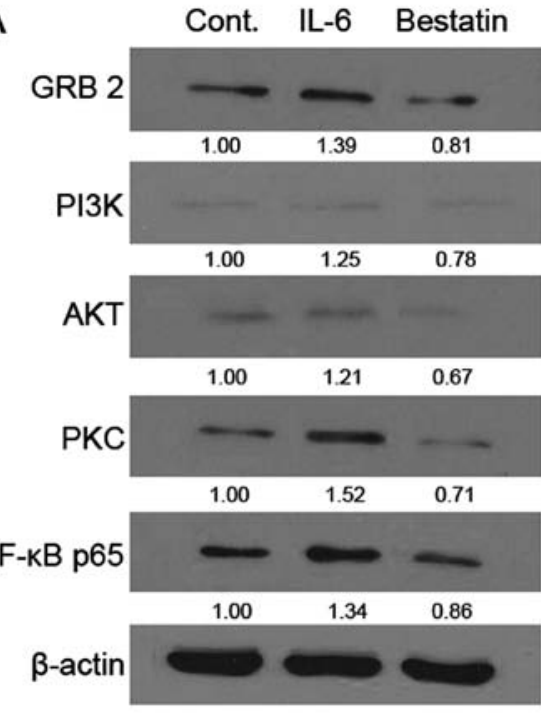

C

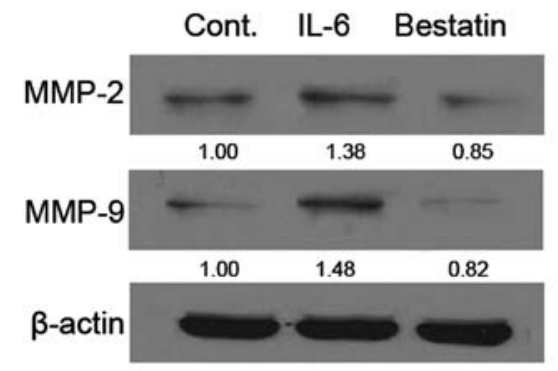

B

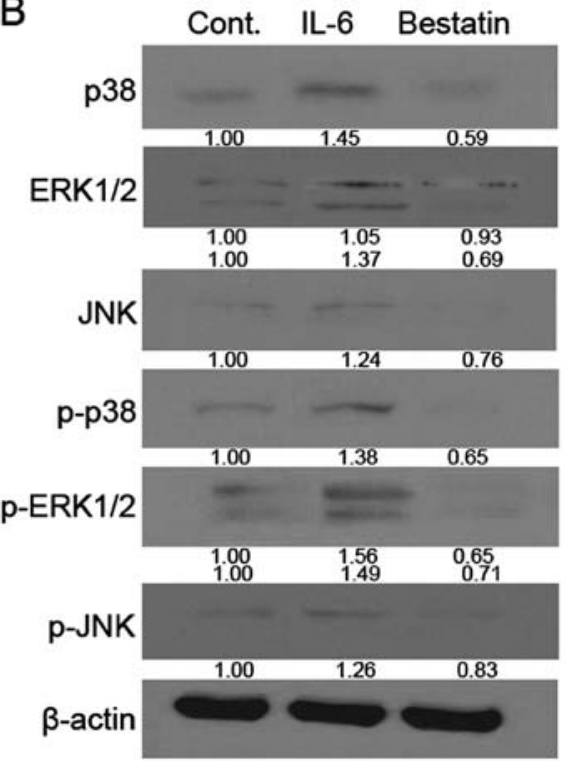

D

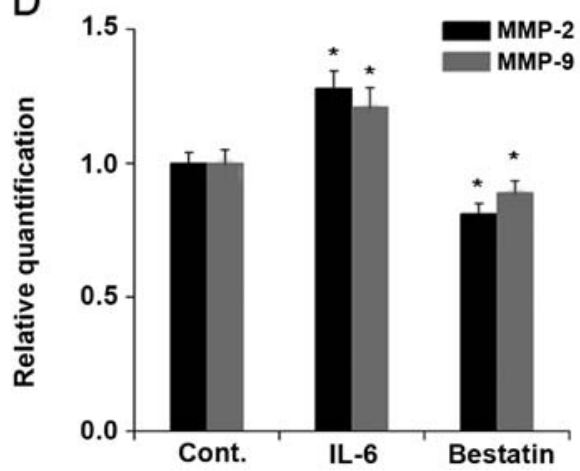

Figure 6. Mitogen-activated protein kinase (MAPK) and phosphatidylinositol 3-kinase (PI3K) pathway proteins in interleukin-6 (IL-6)- and bestatin-treated U-2 OS cells. Cells were treated with IL-6 and bestatin for 24 h. The levels of (A) GRB2, PI3K, AKT, PKC, NF-кB p65; (B) p38, ERK1/2, JNK, p-p38, p-ERK1/2 and p-JNK; (C) matrix metalloproteinase (MMP)-2 and -9 were depicted by SDS-PAGE and western blotting. Results shown are representative of at least three independent experiments. (D) Relative quantification of MMP-2 and -9 by real-time PCR. The ratios between MMP-2, -9 and GAPDH mRNA are displayed and data represent the mean \pm standard deviation (SD) in duplicate of at least three independent experiments. ${ }^{*} \mathrm{P}<0.05$ was considered significant.

AKT, PKC, NF- $\kappa$ B p65 (Figs. 5A and 6A), p38, ERK1/2, JNK, p-p38, p-ERK1/2 and p-JNK (Figs. 5B and 6B). Together these results show that a reduction of APN activity in osteosarcoma cells dampens MAPK and PI3K signalling, as shown by the reduced levels of phosphorylated p38, ERK1/2 and JNK. This raises the possibility that APN might have a signalling function in osteosarcoma invasiveness by activating the transcription factor $\mathrm{NF}-\kappa \mathrm{B}$ through the MAPK and PI3K pathways. NF- $\kappa \mathrm{B}$ would then activate downstream target genes such as MMP-2 and -9 .

We next investigated whether the enzymatic activity changes in MMP-2 and -9 upon bestatin or IL-6 treatment could be due to reduced MMP- 2 and -9 protein levels. Indeed, we showed by western blotting that the treatment of MG63 (Fig. 5) and U-2 OS (Fig. 6) cell lines with bestatin $(100 \mu \mathrm{M})$ for $24 \mathrm{~h}$ resulted in decreased levels of MMP-2 and -9 (Figs. 5C and 6C). By comparison, the treatment of with APN stimulator IL-6 resulted in increased levels of MMP-2 and -9 (Figs. 5C and 6C). We next determined MMP-2 and -9 mRNA levels by quantitative PCR and found that these were reduced upon bestatin treatment and increased upon IL-6 treatment. The changes in MMP-2 and -9 protein and mRNA levels (Figs. 5D and 6D) are therefore in accordance with the changes in MMP-2 and -9 activity (Fig. 4).

Effect of IL- 6 and bestatin on NF- $\kappa B$ p 65 signalling. Western blotting revealed that IL- 6 and bestatin treatments increased and decreased, respectively, the levels of the transcription factor $\mathrm{NF}-\kappa \mathrm{B}$, which has been shown to activate MMP-1, -3 and -9 transcription (49). We therefore investigated the expression and localization of NF- $\mathrm{BB}$ in IL- 6 or bestatin-treated MG63 and U-2 OS cells by immunocytochemisty with an antibody against the p65 subunit. In untreated cells, NF- $\kappa \mathrm{B}$ was visible in both the cytosol and nucleus (control panel in Fig. 7A and B). The cytoplasmic form is inactive due to its association with inhibitory protein I $\kappa$ B. IL-6 treatment concentrated the NF- $\kappa$ B p65 in the nucleus (Fig. 7A and B), while bestatin reduced overall NF- $\mathrm{B}$ p65 levels, consistent with our western blotting data (Fig. 5). These results support our model of MMP-2 and -9 activation by NF- $\mathrm{B}$, which has been activated by APN signalling via the MAPK or PI3K pathway. 
A

MG63

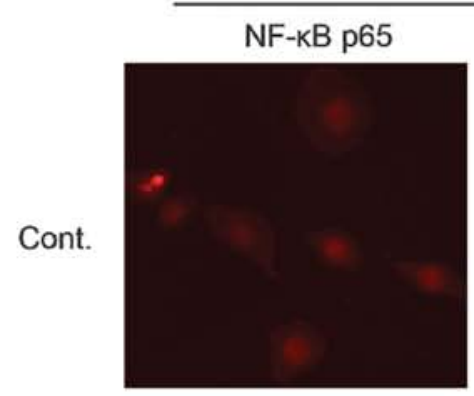

Nuclear

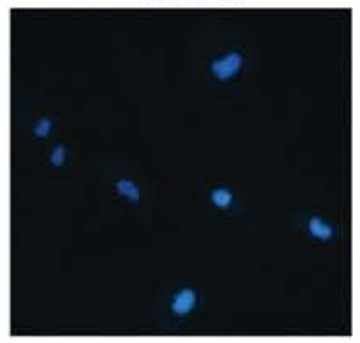

Merge

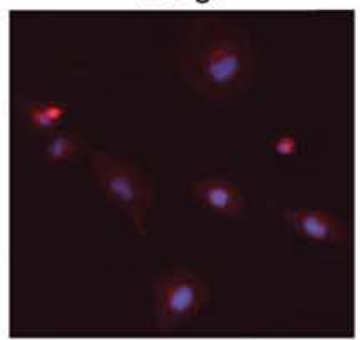

IL-6
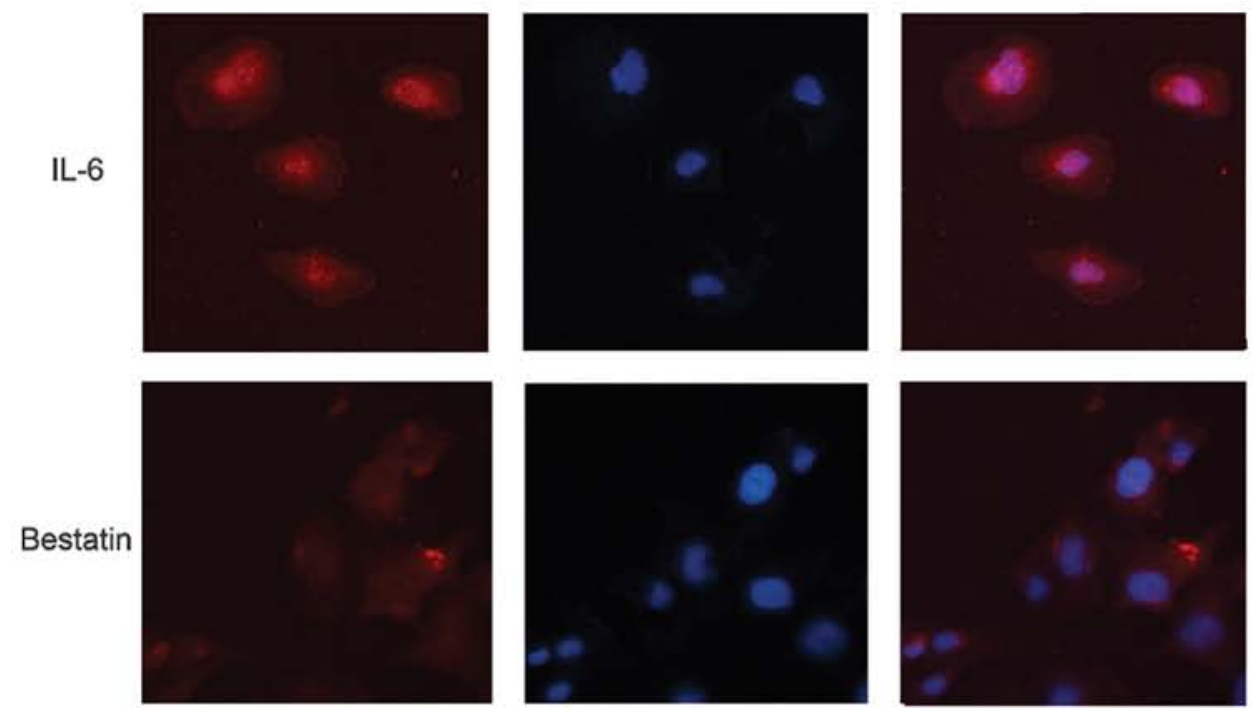

B

U-2 OS

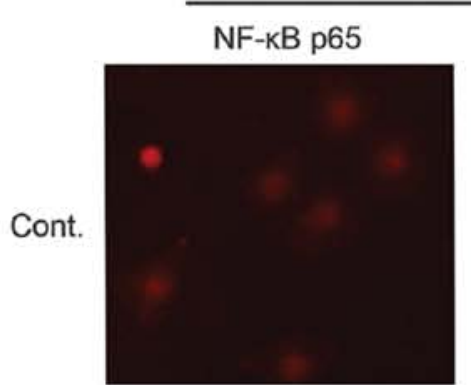

Nuclear

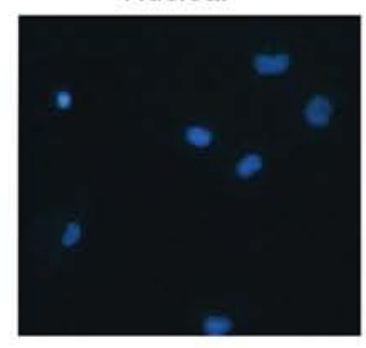

Merge
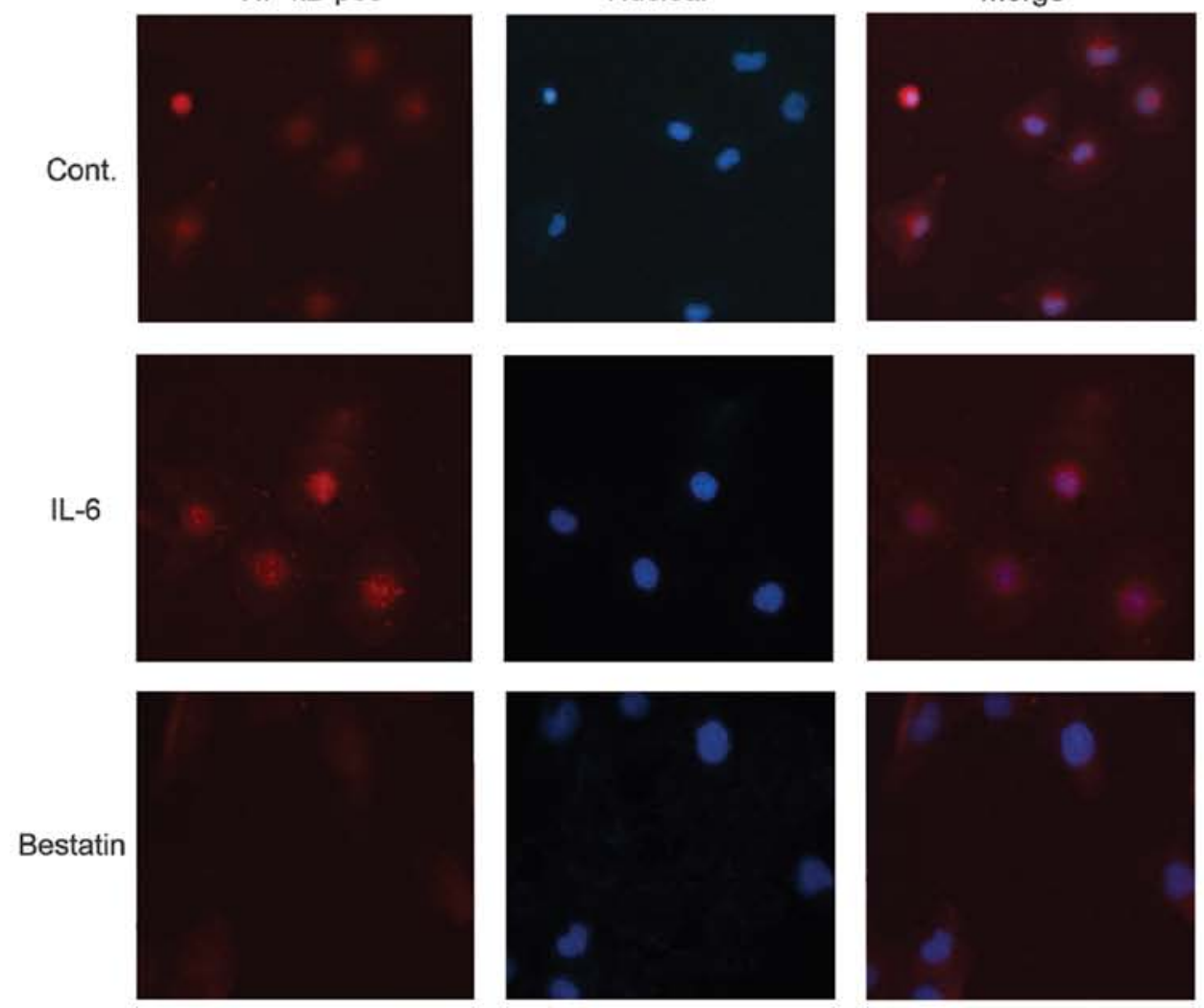

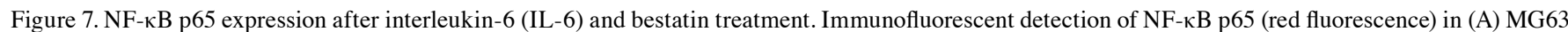
and (B) U-2 OS cultures treated with IL-6 $(1 \mathrm{nM})$ or bestatin $(100 \mu \mathrm{M})$ for $24 \mathrm{~h}$. Nuclei were counterstained with propidium iodide (blue fluorescence). Photomicrographs were obtained using a Leica TCS SP2 confocal spectral microscope. 


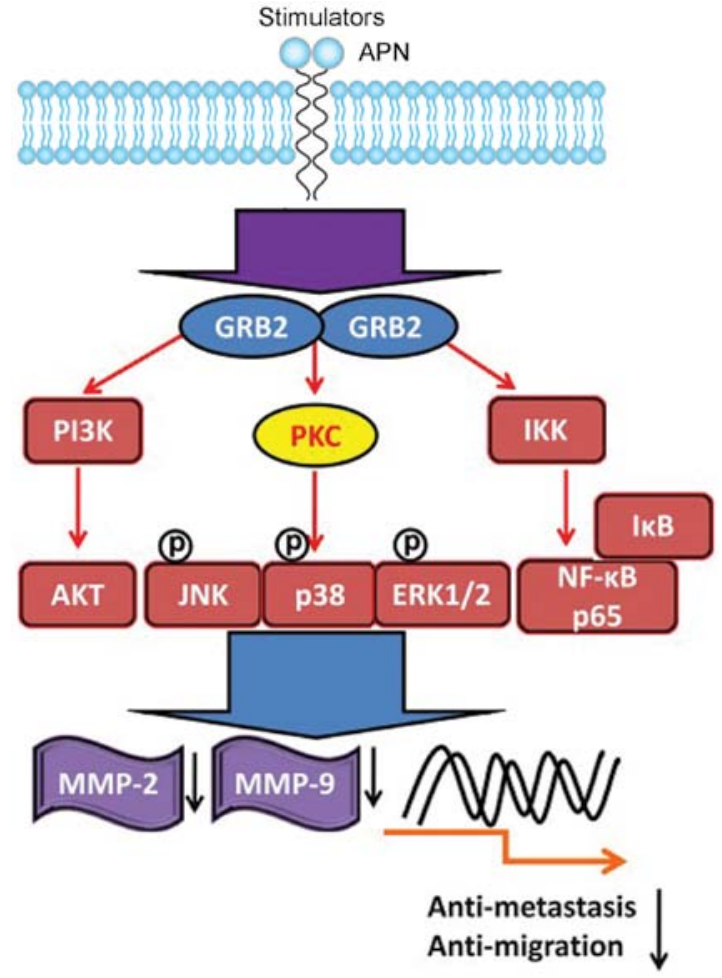

Figure 8. Possible signalling pathways activated by APN that mediate cell invasion and migration in human osteosarcoma cells. Image adapted from Liao et al (56).

\section{Discussion}

Our study supports the involvement of enzymatic and signalling functions of APN in osteosarcoma invasion. Foremost, the inhibition by bestatin of APN in osteosarcoma cell lines reduces cell invasiveness and migration potential concomitant with a downregulation of APN mRNA and hydrolysing activity. Reduced cell motility is accompanied by reduced MAPK and PI3K signalling and reduced levels of transcription factor NF- $\kappa$ B, and its targets MMP-2 and -9 . Together these data support the notion that the reduced invasiveness is caused by reduced APN enzymatic and signalling activity. That is, APN enzymatic activity not only degrades the ECM to facilitate migration but also activates the MAPK and PI3K pathway, leading to activation of MMP-2 and -9. These data place APN in a potentially important position for regulating key signalling pathways which activate MMP-2 and -9 via MAPK and $\mathrm{NF}-\kappa \mathrm{B}$ to promote invasiveness (Fig. 8). Since bestatin is an inhibitor of various leucine and arginine aminopeptidases and an efficient inhibitor of LTA4 hydrolase and lacks selectivity toward exopeptidases (50), further experiments are required to determine whether the decreases in APN, MMP-2 and -9 activity were caused exclusive by bestatin inhibition of APN or its inhibition of other molecules. An exclusive role of APN in activating signalling pathways and MMP-2 and -9 activity was demonstrated with gene silencing of APN by small interfering RNA.

We also show that IL-6 treatment of osteosarcoma cell lines increases cell invasiveness and migration potential concomitant with an upregulation of APN mRNA and hydrolysing activity. Increased cell motility is accompanied by activation of the MAPK and the PI3K signalling pathways. IL-6 treatment also increased levels of transcription factor $\mathrm{NF}-\kappa \mathrm{B}$, and its targets MMP-2 and -9. This supports the possibility that APN activation promotes cell invasiveness. It has previously been shown that inflammatory cytokines such as IL-6 increase the invasive capacity of malignant cells $(15,51-53)$. An involvement of APN in IL-6-induced osteosarcoma invasiveness has already been suggested because invasiveness correlates with the increased relative enzymatic activity of APN and APN inhibitor bestatin reduces IL-6-induced invasiveness (24). These data do not exclude the possibility that APN activates MMP-2 and -9 via MAPK activation of NF- $\kappa$ B. However, further experiments are required to exclude the involvement of other factors known to be induced by IL-6. For example IL-6 activation of intercellular adhesion molecule-1 (ICAM-1) via the integrin-linked kinase (ILK)/AKT/AP-1 pathway promotes osteosarcoma cell motility (15). IL-6 also promotes invasion and migration of human osteosarcoma cell lines through the signal transducer and activator of transcription 3 (STAT3) signalling pathway (54). Thus to exclude the possibility that our observed effects are due to APN activation and not other IL-6 downstream effectors, a specific activation of APN would be required.

Inflammatory cytokine IL-6 treatment resulted in an activation of all three arms of the MAPK signalling pathway, which regulates diverse processes including gene expression and cell morphology (48). Specifically, we observed increased levels of phosphorylated p38, ERK1/2 and JNK. In addition, IL-6 treatment increased the protein levels of these three MAPKs. Furthermore, levels of NF- $\kappa \mathrm{B}$ p65, a downstream effector of IL-6 signalling and a MAPK substrate, were increased. Our analysis of signalling pathway proteins also revealed that IL-6 altered expression levels of PI3K, AKT and PKC, members of the PI3K signalling pathway, whose activation in tumours contributes to metastatic competence (47). In contrast, bestatin had the opposite effect. Together these data establish a signalling footprint of IL-6-stimulated osteosarcoma cells and represent a platform on which to explore crosstalk with signalling pathways activated by APN.

APN performs multiple functions by numerous mechanisms, including the enzymatic cleavage of peptides, endocytosis and signal transduction (55). The strong correlation of APN expression and enzymatic activity with the invasive capacity of numerous cell types makes it an attractive target molecule for therapy. Our study raises the possibility that APN is involved in osteosarcoma metastasis and that its functions do not always depend on its enzymatic activity. APN performs multiple functions by numerous mechanisms, including the enzymatic cleavage of peptides, endocytosis and signal transduction (56). Our study suggests that these mechanisms also occur in osteosarcoma, and lays the foundation for future studies.

\section{Acknowledgements}

The study was supported by the Natural Science Foundation of Zhejiang province (LY13H060005), Public Technology Applied Research Projects of Zhejiang province (2014C33254), General Foundation of Zhejiang province (2013KYA201), General Research Plan B of Zhejiang province (2012KYB213), and Shaoxing Science Project (2013B70081). 


\section{References}

1. Ottaviani G and Jaffe N: The epidemiology of osteosarcoma Cancer Treat Res 152: 3-13, 2009.

2. Sung L, Anderson JR, Donaldson SS, Spunt SL, Crist WM, Pappo AS; Soft Tissue Sarcoma Committee of the Children's Oncology Group: Late events occurring five years or more after successful therapy for childhood rhabdomyosarcoma: a report from the Soft Tissue Sarcoma Committee of the Children's Oncology Group. Eur J Cancer 40: 1878-1885, 2004.

3. Cheng YY, Huang L, Lee KM, Li K and Kumta SM: Alendronate regulates cell invasion and MMP-2 secretion in human osteosarcoma cell lines. Pediatr Blood Cancer 42: 410-415, 2004.

4. Cho HJ, Lee TS, Park JB, et al: Disulfiram suppresses invasive ability of osteosarcoma cells via the inhibition of MMP-2 and MMP-9 expression. J Biochem Mol Biol 40: 1069-1076, 2007.

5. Xin ZF, Kim YK and Jung ST: Risedronate inhibits human osteosarcoma cell invasion. J Exp Clin Cancer Res 28: 105, 2009.

6. Fan DG, Dai JY, Tang J, et al: Silencing of calpain expression reduces the metastatic potential of human osteosarcoma cells. Cell Biol Int 33: 1263-1267, 2009.

7. Dass CR, Nadesapillai AP, Robin D, et al: Downregulation of uPAR confirms link in growth and metastasis of osteosarcoma. Clin Exp Metastasis 22: 643-652, 2005.

8. Wan X, Kim SY, Guenther LM, et al: Beta4 integrin promotes osteosarcoma metastasis and interacts with ezrin. Oncogene 28: 3401-3411, 2009.

9. Haydon RC, Deyrup A, Ishikawa A, et al: Cytoplasmic and/or nuclear accumulation of the beta-catenin protein is a frequent event in human osteosarcoma. Int J Cancer 102: 338-342, 2002.

10. Iwaya K, Ogawa H, Kuroda M, Izumi M, Ishida T and Mukai K: Cytoplasmic and/or nuclear staining of beta-catenin is associated with lung metastasis. Clin Exp Metastasis 20: 525-529, 2003.

11. Engin F, Bertin T, Ma O, et al: Notch signaling contributes to the pathogenesis of human osteosarcomas. Hum Mol Genet 18: 1464-1470, 2009.

12. Hughes DP: How the NOTCH pathway contributes to the ability of osteosarcoma cells to metastasize. Cancer Treat Res 152: 479-496, 2009.

13. Leow PC, Tian Q, Ong ZY, Yang Z and Ee PL: Antitumor activity of natural compounds, curcumin and PKF118-310, as Wnt $/ \beta$-catenin antagonists against human osteosarcoma cells. Invest New Drugs 28: 766-782, 2010.

14. Li Y, Zhang J, Ma D, et al: Curcumin inhibits proliferation and invasion of osteosarcoma cells through inactivation of Notch-1 signaling. FEBS J 279: 2247-2259, 2012.

15. Lin YM, Chang ZL, Liao YY, Chou MC and Tang CH: IL-6 promotes ICAM-1 expression and cell motility in human osteosarcoma. Cancer Lett 328: 135-143, 2013.

16. Berdiaki A, Datsis GA, Nikitovic D, et al: Parathyroid hormone $(\mathrm{PTH})$ peptides through the regulation of hyaluronan metabolism affect osteosarcoma cell migration. IUBMB Life 62: 377-386, 2010.

17. Yang R, Hoang BH, Kubo T, et al: Over-expression of parathyroid hormone Type 1 receptor confers an aggressive phenotype in osteosarcoma. Int J Cancer 121: 943-954, 2007.

18. Dobashi Y, Watanabe H, Matsubara M, et al: Autocrine motility factor/glucose-6-phosphate isomerase is a possible predictor of metastasis in bone and soft tissue tumours. J Pathol 208: 44-53, 2006.

19. Niinaka Y, Harada K, Fujimuro M, et al: Silencing of autocrine motility factor induces mesenchymal-to-epithelial transition and suppression of osteosarcoma pulmonary metastasis. Cancer Res 70: 9483-9493, 2010.

20. Fromigue O, Hamidouche Z, Vaudin P, et al: CYR61 downregulation reduces osteosarcoma cell invasion, migration, and metastasis. J Bone Miner Res 26: 1533-1542, 2011.

21. Bauvois B: Transmembrane proteases in cell growth and invasion: new contributors to angiogenesis? Oncogene 23: 317-329, 2004.

22. Carl-McGrath S, Lendeckel U, Ebert $M$ and Röcken $C$ Ectopeptidases in tumour biology: a review. Histol Histopathol 21: 1339-1353, 2006.

23. Hitzerd SM, Verbrugge SE, Ossenkoppele G, Jansen G and Peters GJ: Positioning of aminopeptidase inhibitors in next generation cancer therapy. Amino Acids 46: 793-808, 2014.

24. Kido A, Krueger S, Haeckel C and Roessner A: Possible contribution of aminopeptidase N (APN/CD13) to invasive potential enhanced by interleukin- 6 and soluble interleukin- 6 receptor in human osteosarcoma cell lines. Clin Exp Metastasis 17: 857-863, 1999.
25. Fujii H, Nakajima M, Saiki I, Yoneda J, Azuma I and Tsuruo T: Human melanoma invasion and metastasis enhancement by high expression of aminopeptidase N/CD13. Clin Exp Metastasis 13: 337-344, 1995.

26. Kehlen A, Lendeckel U, Dralle H, Langner J and Hoang-Vu C: Biological significance of aminopeptidase N/CD13 in thyroid carcinomas. Cancer Res 63: 8500-8506, 2003.

27. Petrovic N, Schacke W, Gahagan JR, et al: CD13/APN regulates endothelial invasion and filopodia formation. Blood 110: 142-150, 2007.

28. Hong DY, Lee BJ, Lee JC, Choi JS, Wang SG and Ro JH: Expression of VEGF, HGF, IL-6, IL-8, MMP-9, telomerase in peripheral blood of patients with head and neck squamous cell carcinoma. Clin Exp Otorhinolaryngol 2: 186-192, 2009.

29. Loo WT, Sasano H and Chow LW: Pro-inflammatory cytokine, matrix metalloproteinases and TIMP-1 are involved in wound healing after mastectomy in invasive breast cancer patients. Biomed Pharmacother 61: 548-552, 2007.

30. Güllü IH, Kurdoğlu M and Akalin I: The relation of gelatinase (MMP-2 and -9) expression with distant site metastasis and tumour aggressiveness in colorectal cancer. Br J Cancer 82: $249,2000$.

31. Mizutani K, Kofuji K and Shirouzu K: The significance of MMP-1 and MMP-2 in peritoneal disseminated metastasis of gastric cancer. Surg Today 30: 614-621, 2000.

32. Korpi JT, Hagström J, Lehtonen N, et al: Expression of matrix metalloproteinases-2, $-8,-13,-26$, and tissue inhibitors of metalloproteinase-1 in human osteosarcoma. Surg Oncol 20: e18-e22, 2011.

33. Ferrari C,Benassi S, Ponticelli F, et al: Role of MMP-9 and its tissue inhibitor TIMP-1 in human osteosarcoma: findings in 42 patients followed for 1-16 years. Acta Orthop Scand 75: 487-491, 2004.

34. Foukas AF, Deshmukh NS, Grimer RJ, Mangham DC, Mangos EG and Taylor S: Stage-IIB osteosarcomas around the knee. A study of MMP-9 in surviving tumour cells. J Bone Joint Surg Br 84: 706-711, 2002.

35. Himelstein BP, Asada N, Carlton MR and Collins MH: Matrix metalloproteinase-9 (MMP-9) expression in childhood osseous osteosarcoma. Med Pediatr Oncol 31: 471-474, 1998.

36. Bellido T, O'Brien CA, Roberson PK and Manolagas SC: Transcriptional activation of the p21(WAF1,CIP1,SDI1) gene by interleukin-6 type cytokines. A prerequisite for their pro-differentiating and anti-apoptotic effects on human osteoblastic cells. J Biol Chem 273: 21137-21144, 1998.

37. Franchimont N, Gangji V, Durant D and Canalis E: Interleukin-6 with its soluble receptor enhances the expression of insulin-like growth factor-I in osteoblasts. Endocrinology 138: 5248-5255, 1997.

38. Jilka RL, Weinstein RS, Bellido T, Parfitt AM and Manolagas SC: Osteoblast programmed cell death (apoptosis): modulation by growth factors and cytokines. J Bone Miner Res 13: 793-802, 1998.

39. Nishimura R, Moriyama K, Yasukawa K, Mundy GR and Yoneda T: Combination of interleukin- 6 and soluble interleukin- 6 receptors induces differentiation and activation of JAK-STAT and MAP kinase pathways in MG-63 human osteoblastic cells. J Bone Miner Res 13: 777-785, 1998.

40. Kehlen A, Göhring B, Langner J and Riemann D: Regulation of the expression of aminopeptidase A, aminopeptidase N/CD13 and dipeptidylpeptidase IV/CD26 in renal carcinoma cells and renal tubular epithelial cells by cytokines and cAMP-increasing mediators. Clin Exp Immunol 111: 435-441, 1998.

41. Chen YY, Chiang SY, Lin JG, et al: Emodin, aloe-emodin and rhein inhibit migration and invasion in human tongue cancer SCC-4 cells through the inhibition of gene expression of matrix metalloproteinase-9. Int J Oncol 36: 1113-1120, 2010.

42. Lin CC, Chen JT, Yang JS, et al: Danthron inhibits the migration and invasion of human brain glioblastoma multiforme cells through the inhibition of mRNA expression of focal adhesion kinase, Rho kinases-1 and metalloproteinase-9. Oncol Rep 22: 1033-1037, 2009.

43. Lai KC, Huang AC, Hsu SC, et al: Benzyl isothiocyanate (BITC) inhibits migration and invasion of human colon cancer HT29 cells by inhibiting matrix metalloproteinase-2/-9 and urokinase plasminogen (uPA) through PKC and MAPK signaling pathway. J Agric Food Chem 58: 2935-2942, 2010.

44. Liu KC, Huang AC, Wu PP, et al: Gallic acid suppresses the migration and invasion of PC-3 human prostate cancer cells via inhibition of matrix metalloproteinase-2 and -9 signaling pathways. Oncol Rep 26: 177-184, 2011. 
45. Chiang JH, Yang JS, Ma CY, et al: Danthron, an anthraquinone derivative, induces DNA damage and caspase cascades-mediated apoptosis in SNU-1 human gastric cancer cells through mitochondrial permeability transition pores and Bax-triggered pathways. Chem Res Toxicol 24: 20-29, 2011

46. Wen YF, Yang JS, Kuo SC, et al: Investigation of anti-leukemia molecular mechanism of ITR-284, a carboxamide analog, in leukemia cells and its effects in WEHI-3 leukemia mice. Biochem Pharmacol 79: 389-398, 2010.

47. Hennessy BT, Smith DL, Ram PT, Lu Y and Mills GB: Exploiting the PI3K/AKT pathway for cancer drug discovery. Nat Rev Drug Discov 4: 988-1004, 2005.

48. Qi M and Elion EA: MAP kinase pathways. J Cell Sci 118: 3569-3572, 2005.

49. Bond M, Chase AJ, Baker AH and Newby AC: Inhibition of transcription factor NF-kappaB reduces matrix metalloproteinase-1, -3 and -9 production by vascular smooth muscle cells. Cardiovasc Res 50: 556-565, 2001.

50. Bauvois B and Dauzonne D: Aminopeptidase-N/CD13 (EC 3.4.11.2) inhibitors: chemistry, biological evaluations, and therapeutic prospects. Med Res Rev 26: 88-130, 2006.
51. Balkwill F, Charles KA and Mantovani A: Smoldering and polarized inflammation in the initiation and promotion of malignant disease. Cancer Cell 7: 211-217, 2005.

52. Lo CW, Chen MW, Hsiao M, et al: IL-6 trans-signaling in formation and progression of malignant ascites in ovarian cancer. Cancer Res 71: 424-434, 2011.

53. Tang CH, Chen CF, Chen WM and Fong YC: IL-6 increases MMP-13 expression and motility in human chondrosarcoma cells. J Biol Chem 286: 11056-11066, 2011.

54. Tu B, Du L, Fan QM, Tang Z and Tang TT: STAT3 activation by IL- 6 from mesenchymal stem cells promotes the proliferation and metastasis of osteosarcoma. Cancer Lett 325: 80-88, 2012.

55. Mina-Osorio P: The moonlighting enzyme CD13: old and new functions to target. Trends Mol Med 14: 361-371, 2008.

56. Liao CL, Lai KC, Huang AC, et al: Gallic acid inhibits migration and invasion in human osteosarcoma U-2 OS cells through suppressing the matrix metalloproteinase-2/-9, protein kinase $\mathrm{B}$ (PKB) and PKC signaling pathways. Food Chem Toxicol 50: $1734-1740,2012$ 